\title{
The CAI-NPD-Systems Maturity Model as Forecasting Method: From Closed CAI 1.0 to Holistic CAI 2.0 Solutions
}

\author{
Stefan Hüsig \\ Management of Innovation and Technology, University of Regensburg \\ 93040 Regensburg; Germany \\ Tel.: +49 (0)941 943-3228, Fax: +49 (0)941 943-3230 \\ stefan.huesig@wiwi.uni-regensburg.de
}

\begin{abstract}
This article examines current and future developments in the field of CAI using a model called "CAI-NPD-Systems Maturity Model". This model is based on two aspects of the CAI systems development: The development in innovation theory and models such as Stage Gate or Open Innovation, and the development in the technologies-supporting software approaches such as Web2.0 to develop new generations of CAI. As a result, an evolution path from generic IT-support and simple ad-hoc NPD-processes over closed CAI systems to holistic CAI2.0 is proposed. Examples and implications of these trends are specified.
\end{abstract}

Keywords: Closed CAI 1.0, Closed CAI 2.0, Open CAI 2.0, Computer Aided Innovation, Open Innovation, Closed Innovation, Web 2.0, Crowd sourcing, Open Innovation Accelerators, OIA, New Product Development, NPD, CAINPD-Systems Maturity Model.

\section{Introduction}

So far, even holistic CAI-tools in existing categorization schemes were and are primarily focused on firm-internal New Product Development (NPD) concepts like Employee-Driven-Innovation (EDI) and Closed Innovation [1-7]. Their prime concern is to support the organization's own employees and the process of management from invention to innovation by providing methods such as TRIZ, idea or project portfolios, suggestion schemes or variations of the stage gate model. External stakeholders of the innovation process such as customers, users or other interaction with people and organizations outside the company has not played a decisive role in the traditional CAI-concepts so far. Therefore, these traditional CAIapproaches for the closed innovation process are here referred to as "Closed CAI 1.0".

However, due to technological as well as strategic changes, new types of CAI systems emerged. From a technological point of view the use of recent internet programming technologies, i.e. Ajax, RSS feeds and other developments around the Web 2.0-paradigm, allowed a more interactive and intuitive use of web-based applications and therefore opens the access to CAI to a larger audience of

D. Cavallucci, R. De Guio, and G. Cascini (Eds.): CAI 2011, IFIP AICT 355, pp. 29-42, 2011.

(C) IFIP International Federation for Information Processing 2011 
non-professional and untrained users [8-13]. From a strategic point of view companies shifted from the predominantly closed innovation paradigm of the past to the recently popularized open innovation paradigm, and started to inter-act with people and organizations outside the company in order to harvest their innovative capabilities [13-16]. Both developments support each other and led to the widespread growth of various intermediaries that offer web-based platforms and tools on the basis of latest web 2.0 technologies to offer companies access to innovation communities [17]. This development is here referred to as "Open CAI 2.0", which represents the next evolutionary step in the CAI development.

Although, these categories in the CAI development are helpful to distinguish present generations of CAI, they lack a common theoretical underpinning and a framework that would allow forecasting their future development. This paper aims to further develop the "CAI-NPD-Systems Maturity Model" described by Waldmannstetter and Hüsig [6] or Hüsig and Kohn [3] which is based on and inspired by similar approaches, such as those by Bowden [1], Cooper [18, 19] or McGrath [20]. This framework presented here aims to describe, explain and even extrapolate the CAI evolution pattern from "Closed CAI 1.0" to "Holistic CAI 2.0 Solutions".

The paper will be structured as follows. First the CAI-NPD-Systems Maturity Model is briefly described and past and present CAI-tools, categories and NPDmethods are exemplified. Building on these trends, a possible future CAI-roadmap is suggested and new possible stages in the CAI-NPD evolution are integrated into the CAI-NPD-Systems Maturity Model. Implications for new and old CAI-suppliers according to the proposed roadmap including their opportunities and threats are provided.

\section{The CAI-NPD-Systems Maturity Model}

Scholars in process management and information systems have developed a long tradition of analyzing the development of IT usage or process capabilities by what are called maturity or stage models [21, 22]. Maturity models typically consist of a structured collection of elements that describe certain aspects of maturity in an organization. A maturity model can be used as a benchmark to assess different organizations for comparison and is frequently organized in hierarchical stages or levels. One well-established example is Humphrey's Capability Maturity Model (CMM) [21], which is a process capability maturity model to aid the definition and understanding of an organizational process. In the area of CAI and NPD systems, similar approaches are also starting to become popular, such as those by Bowden [1], Cooper [18, 19] or McGrath [20].

For the further development of the CAI field, these models could be important for the formative period of the knowledge creation in the CAI field in three ways: First, CAI-NPD maturity models could provide an orientation for future strategies of both CAI suppliers and developers, and guide buying or implementing decisions by users. Second, these models are also interlinked with the process and management aspects of NPD, thus emphasizing a more holistic approach to CAI system development. And finally, those frameworks could be used as a common theoretical underpinning and a framework that would allow forecasting the future development of CAI and NPD 
systems like the "CAI-NPD-Systems Maturity Model" described by Waldmannstetter and Hüsig [6] or Hüsig and Kohn [3].

The basic propositions of the CAI-NPD-Systems Maturity Model are based on the idea that the need for improvement of the organizational innovation system can be described by the distinctive benefits of the IT-support and the NPD methods used. However, these basic propositions of the model have not been explicitly stated or formalized so far. This further step in formalizing is done here. The starting point to do so are the potential benefits of CAI tools, which can be categorized as efficiency, effectiveness, competence and creativity enhancing $[3,4,6]$. These potential benefits can be summarized as part of the supporting capability which ultimately increases the innovation success of firms [6]. This forms proposition 1:

\section{P1: A higher supporting capability increases the innovation success of the firm.}

The extent to which the potential benefits of CAI systems can be realized depends positively on the level of CAI-category or CAI-Stage and the ability to use the functionality effectively. The technological CAI-stage and the organizational ability to use the functionality of CAI systems effectively are defined as CAI maturity. Therefore, this is presented in proposition 2:

P2: A higher CAI maturity increases the supporting capability of the organization.

Along the lines of the CAI maturity, also the NPD maturity concept assumes that the more elaborated the NPD methods an organization is able to use successfully, the greater the NPD maturity of that organization will be. Furthermore, a greater NPD maturity would translate into a greater supporting capability for the ultimate innovation success. This is summed up in proposition 3:

P3: A higher NPD maturity increases the supporting capability of the organization.

And finally, since most CAI tools are targeted at an explicit NPD task or a process stage, it is assumed that it is necessary to select carefully and match the right tool with the adequate method for the right task and phase of the NPD process as long as the CAI tool is not a holistic solution $[3,6]$. Still, in case of a holistic solution, also a comprehensive NPD-system would be needed to effectively support and utilize it. Moreover, even in this case, the maturity level of the NPD system must be analyzed to provide a sufficient match between CAI and NPD capabilities. Unless CAI or NPD methods are embedded in people's work and processes, it will not be used and their benefits will not be realized. Therefore, the fit between the CAI and the NPD maturity influences the combined CAI-NPD-systems maturity which increases the supporting capability and ultimately the innovation success of the firm. The CAI-NPD-systems maturity fit's influence is described in proposition 4:

P4: A higher CAI-NPD maturity fit increases the positive effect of a higher $C A I$ maturity and NPD maturity on the supporting capability of the organization.

A conceptual model of the basic propositions of the CAI-NPD-Systems Maturity Model is presented in figure 1 . 


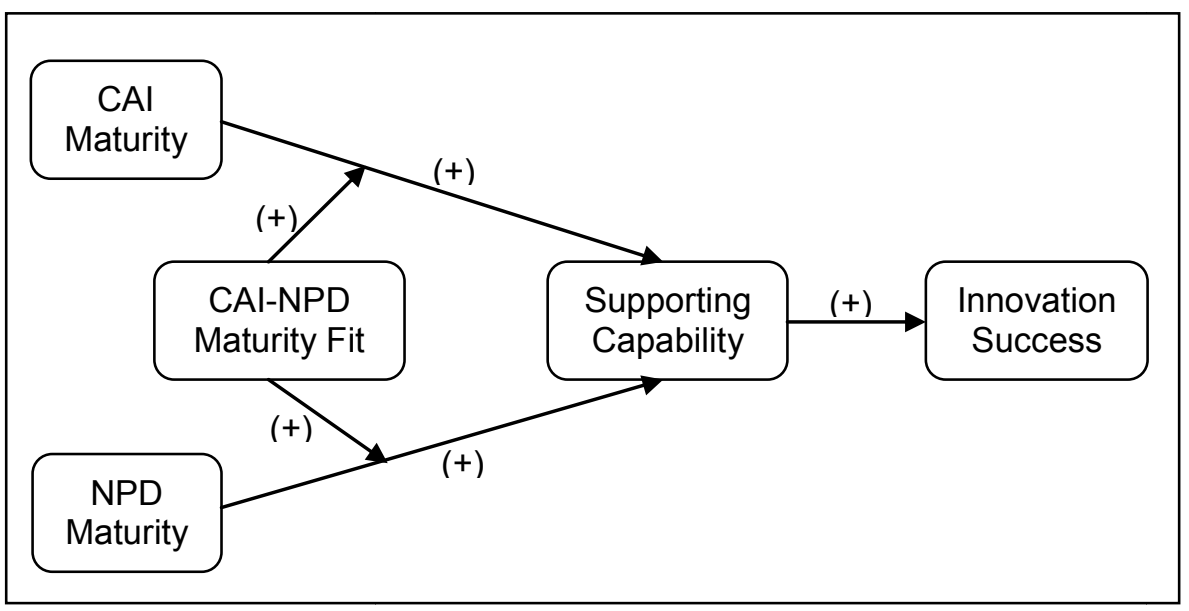

Fig. 1. A conceptual model of the CAI-NPD-Systems Maturity

\subsection{NPD Maturity}

To support this matching process, maturity models for the NPD process developed by Cooper [18, 19] or McGrath [20] might be helpful. In this model, Cooper [18] proposes different maturity stages, which an organization's NPD system must typically pass through. These stages are seen as a kind of natural evolutionary path down which an organization has to go through in its NPD capabilities. The stages are termed "generations", which start at the lowest level with an unmanaged NPD process and ad hoc innovation activities followed by a first generation scheme called "phased review process". In this stage, which was pioneered by NASA in the 1960s and later adopted by the US military, the NPD process is focused on technical milestones only and fails to integrate other functions or customer inputs [18]. The next stage is characterized by like Stage-Gate systems. Firms that use second-generation NPD processes like Stage-Gate systems can overcome some of the limitations of the initial stage and include cross-functional mechanisms and stronger market orientation. The highest level is reached when firms implement a third generation NPD process which is faster, parallel and more flexible than those from the second generation. A third generation NPD process is presented in figure 2 .

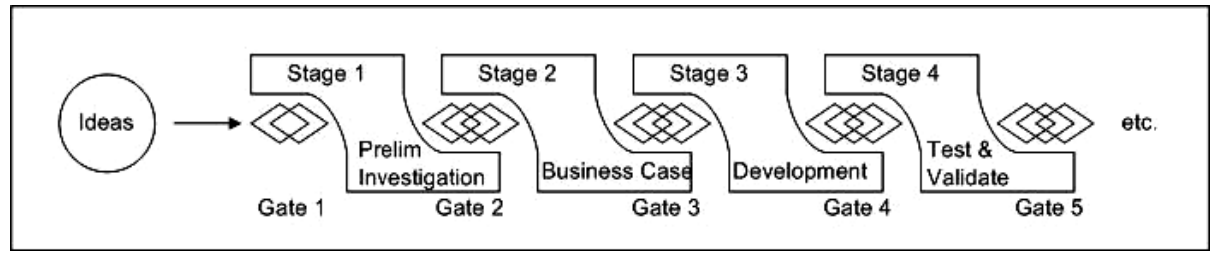

Fig. 2. A third generation NPD process [18, 19] 
According to the logic of the NPD maturity concept, every increase in the generation assumes that the more elaborated the NPD methods and processes an organization is able to use successfully, the greater the NPD maturity of that organization will be, which would translate into a greater supporting capability for the ultimate innovation success. This logic is presented in figure 3.

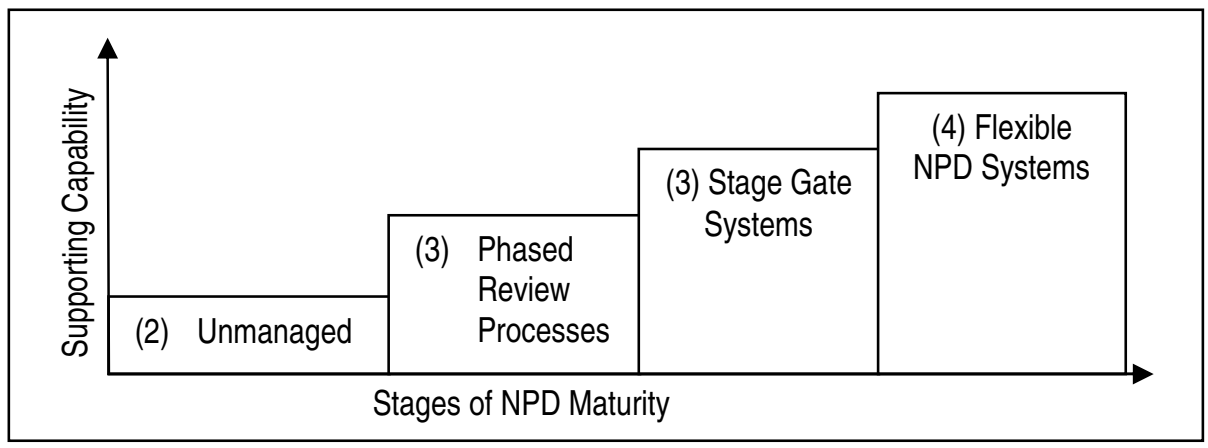

Fig. 3. Stages in NPD-Systems Maturity [6, 3]

\subsection{CAI Maturity}

On the basis of the NPD-Systems Maturity stages, appropriate CAI system stages to the maturity of the NPD system were adjusted [6,3]. To do so, also the CAI systems are organized into a maturity model to match the two systems. As seen in other areas of information systems, also in CAI a tendency towards increasing system integration over formerly separated tools, processes and applications to archive higher levels of ideality is assumed even if not accomplished in all aspects [2, 22]. Using Bowden's [1] maturity model for CAI and combining it with the CAI categorization of Kohn and Hüsig [10], Waldmannstetter and Hüsig [6] organized the maturity of CAI systems into the following stages:

- Stage 0: The organization has no IT-enabled NPD process or uses generic software tools like Excel or Email to support the NPD activities.

- Stage 1: People in the organization are using focused tools for specific NPD tasks, e.g. project management or mind mapping tools.

- Stage 2: Organizations have more holistic solutions that cover the whole process and related activities. The NPD process is widely captured in the IT system. Sopheons Accolade, ID, IntraPro Innovation by XWS or Hype IMT offer integrated CAI solutions which fit into this category.

- Stage 3: Organizations integrated all relevant NPD processes across different business units and departments, and connected other firm process and systems with their CAI system. Unilevers Innovation Process Management System (IPM) or SAP with SAPXPD are said to have achieved that status.

Along the lines of the NPD maturity, also the CAI maturity concept assumes that the higher stage in the CAI development, the greater the CAI maturity of that organization will be. A greater CAI maturity in turn translates into a greater supporting capability for the ultimate innovation success. This logic is presented in figure 4 . 


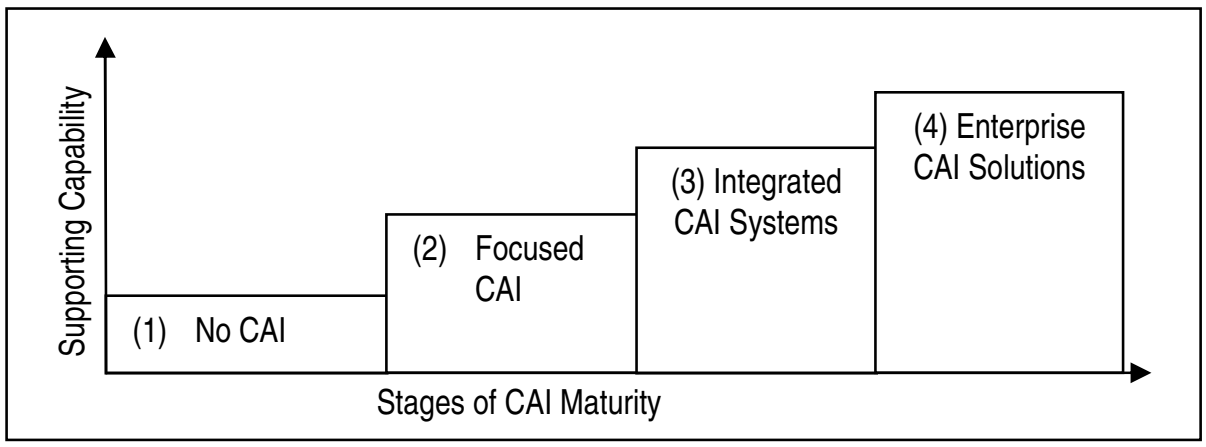

Fig. 4. Stages in CAI-Systems Maturity [6, 3]

Hüsig and Kohn [6] propose that in this maturity model the stages can also be seen as a kind of natural evolution path along which an organization has to proceed. Therefore, this model suggests a staged introduction of CAI tools with respect to the actual stage.

\section{The Updated CAI-NPD-Systems Maturity Model}

The CAI-NPD-Systems Maturity Model as described above is mainly focused on the Closed Innovation paradigm and the Closed CAI 1.0 concept. Therefore, the original model needs to be expanded and is used to further develop the CAI-NPD-Systems roadmap. This adds new stages of maturity on both sides of the model - CAI and NPD capabilities.

\subsection{New NPD Maturity Stages Based on Open Innovation}

First the maturity stages of the organization's NPD system is proposed to be expanded by the Open Innovation concept [13-16]. Open innovation is defined as the use of purposive inflows and outflows of knowledge to accelerate internal innovation, and expand the markets for external use of innovation, respectively [13]. This paradigm assumes that firms can and should use external ideas as well as internal ideas, and internal and external paths to market, as they look to advance their technology. This concept was coined by Henry Chesbrough, based on his research on the innovation practices of large multinational companies. Open innovation is characterized by cooperation for innovation within wide horizontal and vertical networks of universities, start-ups, suppliers, spin-offs, and competitors [14]. Companies can and should use external ideas as well as those from their own R\&D departments, and both internal and external paths like spin-offs or licenses to the market, in order to advance their technology are displayed in figure 5.

Since sources of external information for the innovation process are plentiful, including market actors like customers, suppliers, competitors; the scientific system of university labs and research institutions; public authorities like patent agents and public funding agencies; and mediating parties like technology consultants, media, 


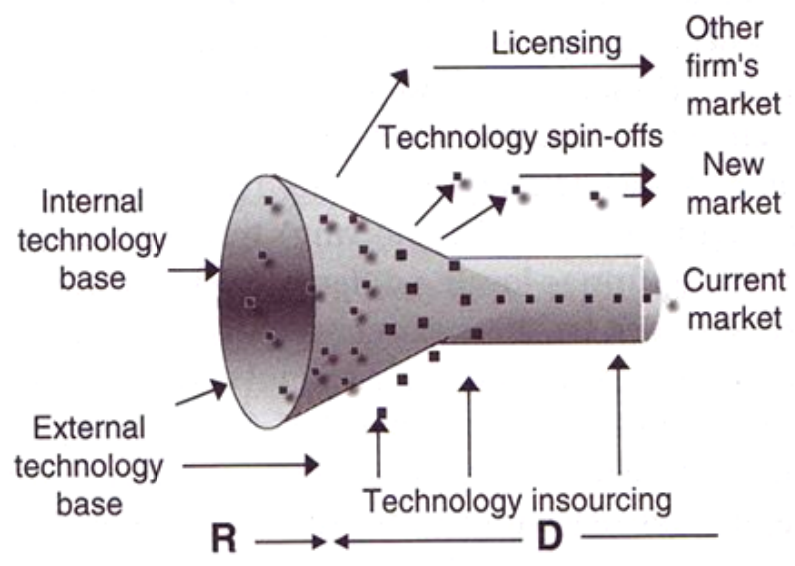

Fig. 5. Open Innovation Process Model [13]

and conference organizers, there are new methods and technologies needed to tap and manage these valuable innovation inputs. By applying these methods for open innovation a firm can overcome its local search bias and acquire precisely the needed information and therefore innovate more successfully and cost efficiently [17]. Main methods used to implement open innovation are:

Lead user method. This method was first developed by Eric von Hippel, who came up with the User/Customer-Driven Innovation paradigm [23]. Von Hippel observed already in the 1980s that the origin of many products and services lays in identifying advanced users - lead users - rather than companies, at the site of implementation and use. Therefore users play a more active and important role than theory had suggested before. Using the lead user method this theory can be applied for improving the innovation output by identifying innovative users and then integrating them by means of innovation workshops. The lead user method also is a proven practice to gather innovative (technological) solutions and so called "need information" which represents the user's experience and requirements [17].

Toolkits for open innovation. These tools are Internet based instruments that aim at supporting users in transferring their needs into new product concepts [17]. Toolkits for user innovation and design are integrated sets of product design, prototyping, and design-testing tools developed to be used by end customers [23]. The goal of a toolkit is to enable non-specialist users to design high-quality, producible custom products that exactly match their requirements. Toolkits often contain "user-friendly" features that guide users at their effort. However, they are restricted to a type of product or service and a specific production system. There are a growing number of firms using these toolkits to address individual requirements substituting market research via direct user-interaction [10]. For example, a toolkit provided to customers interested in designing their own, custom digital semiconductor chips is tailored precisely for that purpose - it cannot be used to design other types of products [23]. Users apply a 
toolkit in conjunction with their rich understanding of their own needs to create a preliminary design, simulate or prototype it, evaluate its functioning in their own use environment, and then iteratively improve it until the design satisfies the particular user need.

Innovation contests. Those contests aim at the generation of input for all stages of the innovation process [17]. In an innovation contest, a company calls on its customers, users, or experts in the general public either to disclose innovative ideas and suggestions for product improvement, or it asks for a very specific solution for a dedicated (technical) innovative task. The contests come in different types. They can be a very broad call for contributions directed at all (potential) customers of the company and/or a very dedicated question to a smaller team of specialists in a specific community. Idea contests can serve to integrate customers, or users typically aim at encouraging innovative ideas at the front end of the innovation process. However, innovation contests can also begin in a later stage in the innovation process; usually in searches for innovative approaches to a technical problem within a broad field of problem solvers. These contests go beyond the user innovation perspective and address the ideas of crowdsourcing when tasks which were traditionally performed by an employee or contractor are outsourced to a group of people or community, through an "open call" to a large group of people (a so called crowd) asking for contributions [13]. Not only at this point Open Innovation and Web2.0 ideas start to overlap significantly. To facilitate these contests, contest organizers are needed to formulate the problem, lay down the rules for participation, usually collects the contributions, evaluates them, and then chooses the winner. Companies have already specialized in acting as an intermediary by organizing idea contests for other organizations. Examples include firms like Hyve AG or Idea Crossing. Typically, these intermediaries are called Open Innovation Accelerators (OIA) [17]. However, idea competitions can also take place within a firm following the EDI/Closed Innovation paradigm typically for traditional CAI. Today, many firms have an intranet portal on which employees can submit their ideas and suggestions for improvement like IBM and their "Innovation Jams" [24]. IBM was so successful internally with this solution that the company now sells the "Jam" idea as a consulting service to other companies becoming a contest organizer.

Stage 4: Flexible NPD System \& FFE-OI. The old model inspired by Cooper [18, 19] exclusively focused on the closed innovation perspective with a strong market and customer orientation but not customer or other stakeholder integration. Therefore, the next evolutionary step in this model should be the introduction of open innovation methods in the NPD capabilities of the next maturity stage. As most firms will use their established close innovation NPD-processes in parallel, Stage 3 is complemented by open innovation methods especially in the fuzzy front end of the innovation process (FFE) and in this way develops the fourth generation: Flexible NPD System with FFE-OI-Methods.

Stage 5: Holistic NPD System. To forecast the future stages in the dominant logic of the NPD-CAI-Systems Maturity Model would suggest that both approaches (Closed Innovation NPD-systems and Open Innovation approaches) unite into a unified fifth 
generation Holistic NPD System in which OI-methods and EDI would be united in a complementary manor. The future NPD system of firms would combine and integrate internal and external communities for the entire innovation process. However, also another scenario could be constructed in which Closed Innovation and hierarchical organized firms will be completely substituted by innovation networks and peer to peer platforms totally based on crowdsourcing, folksonomy and Open Innovation methods going far beyond by Enterprise 2.0 concepts [13, 16, 25]. Nevertheless, the CAI-NPD-Systems Maturity Model would not be suited to be a good theoretical framework for explaining such a radical shift as it assumes a gradual improvement along the maturity and supporting capability dimensions.

\subsection{New CAI Maturity Stages Based on Web 2.0}

In order to support the various methods resulting from the Open and User Innovation Paradigm specific IT-solutions are increasingly developed to enable firm-external participants to integrate more directly in the innovation process [17]. This development expands the traditional CAI-concept towards the Open Innovation sphere. In parallel to the developments in the area of innovation management and theory described in the chapter above parallel progress took place in the area of software which is relevant to the area of CAI. The latter development is frequently described by the term Web 2.0. This terminology lacks a clear definition so far and many discussions about its real content and its future development to Web 3.0 are ongoing $[8,9]$. Nevertheless certain web technology developments in the last 10 years lead to a new breed of web services that have certain elements in common that build the core web 2.0 elements. These core elements are cloud computing, desktop-like usability, interactivity and the semantic web, which are relevant also for the emerging of Open CAI 2.0. These elements and their influence on CAI will be explained in the following:

Cloud computing. Cloud computing is defined as software architecture in which the central software resides not at the location of the user but in the cloud, which typically consists out of one or more central server systems [11]. Cloud computing offers two advantages that are relevant to the evolution of CAI. Cloud services can be accessed easily by users via a network without the need of any installation (=Software as a Service). And cloud computing allows for an easy scalability of the service. This architecture therefore is the prerequisite to allow not only a pre-defined set of users to use and access the CAI infrastructure of a company, but easily grant access to a nearly endless number of users like BMW is doing with its virtual innovation agency. ${ }^{1}$ Cloud computing was also a prerequisite to create open innovation platforms that offer every internet user to participate in many different innovation contests of various companies at the same time, such as Atizo ${ }^{2}$ or Brainfloor.com ${ }^{3}$ are doing.

\footnotetext{
${ }^{1} \mathrm{http}: / /$ www.bmwgroup.com/via/

2 https://www.atizo.com/

${ }^{3}$ http://www.brainfloor.com/
} 
Desktop-like usability. The combination of new web technologies like RSS (Really Simple Syndication), XML (eXtensible Markup Language), JavaScript and others that can be summarized under the term "Ajax" (=Asynchronous JavaScript and XML) allow programmers to develop software that offers rich user interfaces and PCequivalent interactivity and therefore can be used almost like desktop software despite the fact that it is based on a cloud infrastructure [8]. Those Ajax technologies constitute the basis for easy to use interfaces for untrained users to access CAI tools. While Web 1.0 allowed easy access to information to almost all internet users, Ajax allows these users not only to access information, but also to easily create and share information via the web. For innovation contests it is now possible for users to upload drawings, images and other documents to the idea database without any problems.

Interactivity. Based on Ajax as well as RSS technology the web became much more dynamic and interactive. RSS helps users to receive automatic updates on latest changes, Ajax makes it easy to access and to generate information, and both lead therefore to a much more interactive user behavior. Innovation contests therefore do not only mean to collect ideas from outside, but to discuss and thus enrich those ideas during the process. Discussions about the submitted ideas, even idea evaluations by the users based on ratings or even elements of stock-market trading (e.g. offered by the US software company Spigit) are possible because of these interactive possibilities.

Semantic web. The semantic web refers to the new possibilities to create metainformation. [12]. To a certain extent such information can be automatically created, or is created by the many users. Independent from the source of the meta information, this meta information helps to use and process the loads of information created in the Web 2.0. In the context of CAI meta information can e.g. help to cluster ideas in certain categories, it can help to evaluate ideas and extract ideas that were most heavily discussed or ranked best by the users.

These core technologies helped to create from a mainly one-directional web 1.0, which was focused on spreading information from one central source to many different receivers, a web 2.0 that can be characterized by participation of many users, that relies on the collective wisdom of the crowd rather than a single source, that spread from the PC as the predominant device to a platform and device independent architecture, and that is easily to scale. All those changes are being reflected in the latest developments that can be observed in the CAI world. Software applications predominantly are being migrated to central servers in order to allow a broader user base to access them. Usage of idea management systems becomes more interactive and many more ideas and additional information are being generated than in the past. As an example IBM's Idea Jam can be seen. Over a time period of only 90 hours the 2008 edition created over 32,000 posts from participants from over 1,000 companies. [24] Another example is Dell's idea storm that has lead to over 13,000 ideas so far ${ }^{4}$. By looking at the sheer size of these numbers one can imagine that having ideas is not the crucial issue anymore, but being able to a) identify and motivate the relevant users

${ }^{4}$ http://www.ideastorm.com/ 
to participate b) generate and/or collect the relevant ideas and c) sort and analyze the received ideas in an effective way.

Open Innovation Accelerators (OIA). Several start-up companies realized these needs and built their business model around this proposition like the mentioned "Open Innovation Accelerators (OIA)". Based on the newly available web 2.0 technologies and the new open innovation methods several companies started to offer mainly web-based services that offered established companies to utilize the wisdom of the crowd in a relatively easy way in order to increase the efficiency and effectiveness of their innovation process. All those software and service providers can be called OIA and defined as providers of platforms that offer companies the possibility to innovate in cooperation with external actors from the periphery [17]. OIAs typically offer one or several methods of open innovation and, partly, supporting and complementary services for the innovation process. These methods (e.g. lead user, idea contest, toolkit, etc.) are especially focused on the integration of external actors. In consequence, OIAs facilitate a new form of collaboration between an innovating company and its environment. By doing so, OIAs accelerate a company's internal innovation process.

Open CAI 2.0. Summing up, to integrate these new drivers a new concept, called "Open CAI 2.0," was developed. Open CAI 2.0 is proposed as the next evolutionary step in the CAI development trajectory. As pointed out before, Open CAI 2.0 is based on the Web 2.0-paradigm as well as on the OI paradigm. As shown above, new players like OIAs are entering in the CAI-supplier-domain using these core drivers to establish new CAI-based services to support the innovation value chain. Therefore, Open CAI 2.0 can be defined as category of CAI-tools that use technologies following the Web 2.0-paradigm like Cloud computing, desktop-like usability, interactivity and the semantic web to facilitate OI methods such as Lead user, Toolkits and Innovation contests to open the access of organizations to a larger audience of external actors and enable them to interact in different activities of the innovation process. This evolution is also enforced by Open CAI 2.0 tools which support the OI-methods on an outsourced (using one of the OIAs) or self-managed and developed manner (e.g. IBM's innovation jam) especially to support the front-end of the innovation process.

Stage 4: Enterprise CAI 1.0 Solutions \& Open CAI 2.0. As a result, the Stage 4 of the CAI maturity consists of Enterprise CAI Solutions complemented by Open CAI 2.0 tools provided by OIA or self-developed solutions. The traditional Closed CAI 1.0 tools further serve to support the internal innovation process while the Open CAI 2.0 tools typically support the front-end of the innovation process.

Stage 5: Holistic CAI 2.0 Solutions. This development will also be reflected in Stage 5 with Holistic CAI 2.0 Solutions in which Web2.0 technologies as well as integrated internal and external communities are fully incorporated in the firm's open and holistic internal innovation process. A seamless transition over firm and communities boundaries will be enabled by future CAI systems to optimize the full innovation process.

Figure 6 provides the updated CAI-NPD-Systems Maturity Model. 


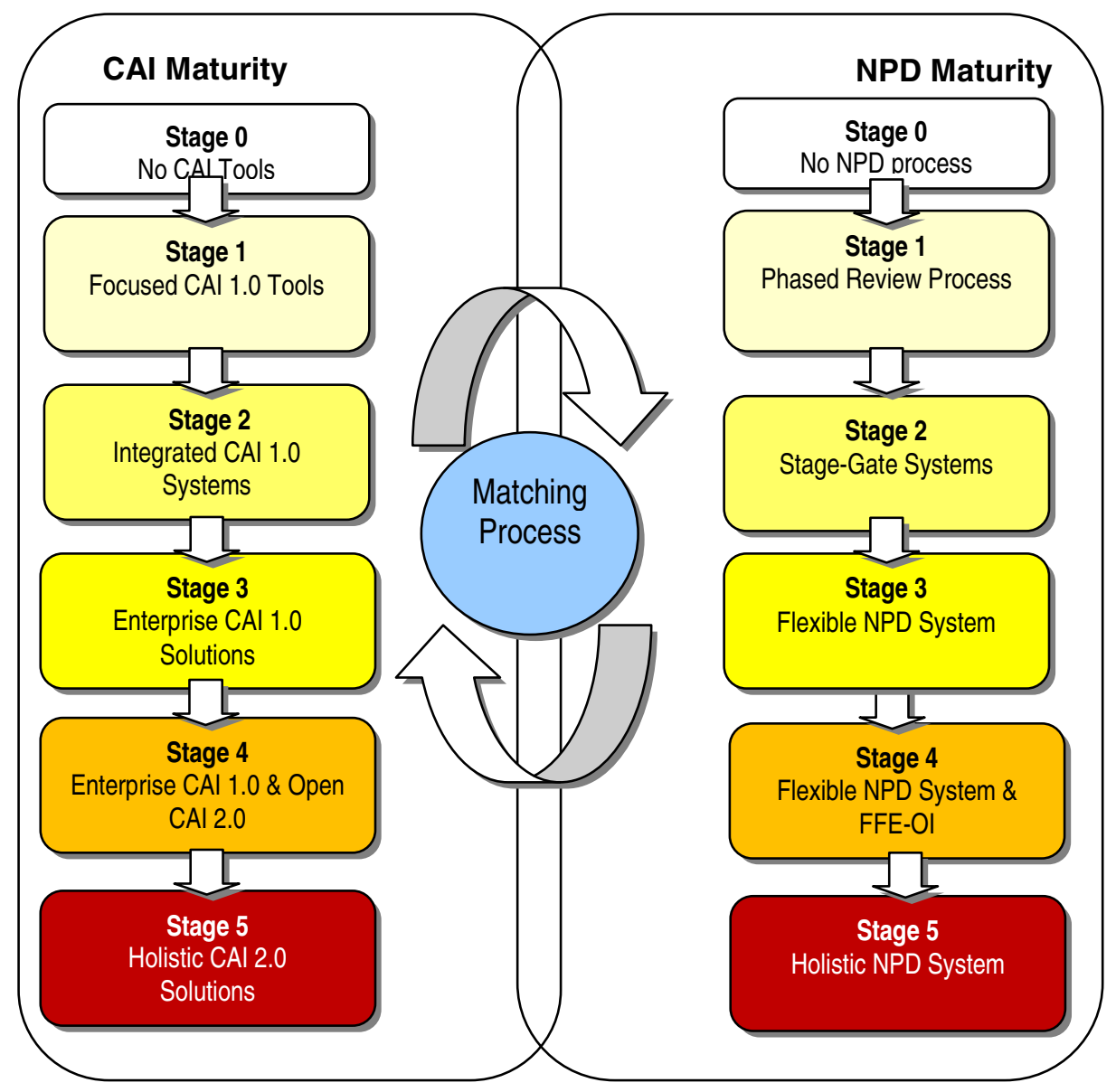

Fig. 6. The updated CAI-NPD-Systems Maturity Model

\section{Implications and Outlook}

In this section a summary of the presented findings is provided and the implications of this research for users, new and old CAI-suppliers are highlighted. This paper shows how the next generations of CAI could look like based on an updated version of the CAI-NPD-Systems Maturity Model by Waldmannstetter and Hüsig [6] or Hüsig and Kohn [3]. Current and next generations of CAI are influenced by technological developments around Web 2.0, which opened the CAI pipeline management software to a broader user base and therefore even for untrained users. At the same time, the Open Innovation paradigm shifted the attention of companies from employees as main suppliers of new ideas to customers and other users outside the company. Both drivers were mutually dependent and amplified each other and therefore led to an enormous increase of potential users and, consequently, to ideas entering the NPD process in established companies. So far, the processes for these 
developments have not been aligned with the existing NPD processes but are handled as separate projects. The integration of Open Innovation activities with the internal NPD system and the development of holistic CAI 2.0 solutions will be major tasks for the companies involved.

For new and old CAI-suppliers the roadmap to Holistic CAI 2.0 Solutions contains likewise opportunities and threats. For traditional CAI 1.0 suppliers it is vital to master the transition to Web2.0 technologies and add Open Innovation methods to their existing products to enable Holistic CAI 2.0 Solutions for their clients in the long run. If they fail to deliver this additional functionality, OIA have the opportunity to address this gap and expand their services and technologies into the traditional domain of CAI 1.0 coming largely from the outside and addressing the FFE. The complementary nature for the development trajectory also offers a cooperative solution in which both, new and old CAI-suppliers could unite their particular capabilities to realize Holistic CAI 2.0 Solutions.

However, also an alternative scenario could be constructed in which Closed Innovation and hierarchical organized firms will be completely substituted by innovation networks and peer to peer platforms totally based on crowdsourcing, folksonomy and Open Innovation methods going far beyond by Enterprise 2.0 concepts [13, 16, 25]. Nevertheless, the CAI-NPD-Systems Maturity Model would not be suited to be a good theoretical framework for explaining such a radical shift as it assumes a gradual improvement along the maturity and supporting capability dimensions. This limits the proposed approach and should be analyzed by using different frameworks based on theories like S-Curve or Disruptive Innovation in which the initial worse supporting capability of Web2.0 based CAI approaches as web applications and the less trained user base can be considered more [26].

Future research should focus on the further development of such concepts and solutions outlined in this paper. In particular, more empirical based inquiries are needed if and how the proposed relationships of the updated CAI-NPD-Systems Maturity Model can be supported or alternative approaches are a more fruitful avenue for research.

\section{References}

1. Bowden, M.: The Role of IT in New Product Development Today. Visions 1, 1-8 (2004)

2. Leon, N.: The Future of Computer-Aided Innovation. Computers in Industry 60(8), 539-550 (2009)

3. Hüsig, S., Kohn, S.: Computer Aided Innovation - State of the Art from a New Product Development Perspective. Computers in Industry 60(8), 551-562 (2009)

4. Hüsig, S., Kohn, S.: Development of an Empirical Based Categorisation Scheme for CAI Software. International Journal of Computer Applications in Technology 30(1/2), 33-46 (2007)

5. Cascini, G., Russo, D.: Computer-Aided Analysis of Patents and Search for TRIZ Contradictions. International Journal of Product Development 4(1-2), 52-67 (2007)

6. Waldmannstetter, K., Hüsig, S.: Innovationsmanagementsoftware: Anforderungen, Potentiale, Marktanalyse und Produktübersicht. WiKu-Verlag - Verlag für Wissenschaft und Kultur, Duisburg (2009) 
7. Dörr, N., Behnken, E., Müller-Prothmann, T.: Web-Based Platform for Computer Aided Innovation - Combining Innovation and Product Lifecycle Management. In: Cascini, G. (ed.) IFIP International Federation for Information Processing. Computer-Aided Innovation (CAI), vol. 277, pp. 229-237. Springer, Boston (2008)

8. O'Reilly, T.: What Is Web 2.0? - Design Patterns and Business Models for the Next Generation of Software,

http: //oreilly.com/web2/archive/what-is-web-20.html

9. O'Reilly, T., Battelle, J.: Web Squared: Web 2.0 Five Years On, http: / /www.web2 summit.com/web2009/public/schedule/ detail/10194

10. Awazu, Y., Baloh, P., Desouza, K.C., Wecht, C., Kim, J.Y., Sanjeev, J.: InformationCommunication Technologies Open up Innovation. Res. Technol. Manag 52(1), 51-58 (2009)

11. Hayes, B.: Cloud Computing. Communications of the ACM 51(7), 9-11 (2008)

12. McIlraith, S., Son, T.C., Zeng, H.: Semantic Web Services. IEEE Intelligent Systems, 46-53 (2001)

13. Howe, J.: Crowdsourcing. In: Why the Power of the Crowd is Driving the Future of Business. Crown Business Publishing, New York (2008)

14. Chesbrough, H.W.: Open Innovation. In: The New Imperative for Creating and Profiting from Technology. Harvard Business School Press, Boston (2003)

15. Chesbrough, H.W.: The Era of Open Innovation. MIT Sloan Management Review 44(3), 35-41 (2003)

16. Chesbrough, H.W.: Open Business Models: How to Thrive in the New Innovation Landscape. Harvard Business School Press, Boston (2006)

17. Diener, K., Piller, F.: The Market for Open Innovation: First Study to Compare the Offerings, Methods, and Competences of Intermediaries, Consultancies, and Brokers for Open Innovation. RWTH-TIM Group, lulu.com. Aachen University, Germany (2010)

18. Cooper, R.G.: Perspective Third-Generation New Product Processes. Journal of Product Innovation Management 11(1), 3-14 (1994)

19. Cooper, R.G.: Winning at New Products - Accelerating the Process from Idea to Launch, 3rd edn. Perseus Books Group, Jackson (2001)

20. McGrath, M.E.: Setting the PACE for Product Development - A Guide to Product and Cycle-time Excellence. Butterworth-Heinemann, Boston (1996)

21. Humphrey, W.S.: Managing the Software Process. Addison Wesley Professional, Reading (1989)

22. Nolan, R.L.: Managing the Computer Resource: A Stage Hypothesis. Communications of the ACM 16(7), 399-405 (1973)

23. von Hippel, E.: Democratizing Innovation. MIT Press, Cambridge (2005)

24. Innovationjam, executive report, ftp: / / ftp.software.ibm.com/common/ssi/pm/xb/n/gbe03165usen/ GBE03165USEN. PDF

25. McAfee, A.P.: Enterprise 2.0: The Dawn of Emergent Collaboration. MIT Sloan Management Review 47(3), 21-28 (2006)

26. Keller, A., Hüsig, S.: Ex ante Identification of Disruptive Innovations in the Software Industry Applied to Web Applications: The Case of Microsoft's vs. Google's Office Applications. Technological Forecasting and Social Change 76, 1044-1054 (2009) 